the bait within the cleared area, or as due to the repellent effect that a bare surface of ground may have on species living in the grass. We are inclined to believe that the first explanation is correct. In the course of our studies on mosquito density we have found that, when the continuity of the savannas is broken by an area devoid of grass, such as a road, the numbers of mosquitoes found on both sides of the clearing are practically the same. In one of our study areas a track made by motor traffic leaving a bare surface of ground $20-30 \mathrm{~m}$. wide produced a clear cut across an expanse of savanna. On one side was left a wide area of savanna with numerous breeding places, on the other side no breeding places were found. The mosquitoes caught resting in the grass must have come across the track, since no suitable breeding place for savanna mosquitoes could be found in the great forest framing this side of the savanna. Using the technique already described ${ }^{2}$ for catching resting mosquitoes, it was found that the mosquito density on the forest side was 3.6 mosquitoes per sq. m. of ground, and on the open side 2.7 mosquitoes per sq. $\mathrm{m}$. This shows in the first place that 20 or $30 \mathrm{~m}$. of bare ground, deterrent as they would be to blood-seeking females, have no effect on mosquitoes dispersing over the savannas; also that the density of mosquitoes tends to be higher away from the breeding places than in their vicinity, which is in agreement with our previous findings ${ }^{2}$.

If the culicines have less difficulty in reaching the bait in a cleared area, this is probably due to their being better able to detect it and being also better fliers. In our previous studies ${ }^{2}$ we found that the "flight-range of dispersal among male anophelines was shorter than the corresponding range of the male culecines. Our present observations seem to point to a shorter range of flight in the blood-seeking anophelines than in the blood-seeking culicine females. A preliminary study on the altitude of flight among the savanna mosquitoes has shown that the culicines usually fly at a higher level than the anophelines. This may account for their greater aptitude for covering wide areas in their dispersal flight and in reaching an animal source of blood, the savanna anophelines flying too near the grass to range as freely. Data on flight-levels were obtained using muslin nets fixed to a moving vohicle, following the technique already described ${ }^{2}$. Two nets were used simultaneously, one fixed at $1.5 \mathrm{~m}$. above the ground, just above the tops of the flowering stems of grass, the other at $4.5 \mathrm{~m}$. above the ground. 3,505 specimens were captured in nine trials, the distribution being as follows:

\begin{tabular}{lcccc} 
& $1 \cdot 5 \mathrm{~m}$. above the ground & \multicolumn{3}{c}{$4 \cdot 5 \mathrm{~m}$. above the ground } \\
& Males & Females & Males & Females \\
Anophelines & 125 & 161 & 139 & 16 \\
Culicines & 495 & 607 & 1,858 & 104
\end{tabular}

Males fly higher than the females of their genus, but culicines taken as a whole tend to fly at a higher level than anophelines. It is curious to observe that such difference in distribution could be detected with a difference in altitude of only three metres. It is worth mentioning here that the vertical distribution of mosquitoes in a forest varies considerably with a small difference in altitude. The stratification of forest mosquitoes was demonstrated for the first time in Villavicencio. In the course of epidemiological studies of jungle yellow fever, Dr. Boshell was able to prove that the vector in the forest, Hoemagogus spegazzinii, could be found only in the upper part of the undisturbed forest ${ }^{3}$. Later, Dr. M. Bates proved that this zonal distribution applies not only to this species but also to many other mosquitoes living in the forest. ${ }^{4}$. The present observations show that the stratification of flying mosquitoes is not limited to the forest but can be found also in a savanna country. A full report on the characteristics of flight of the savanna mosquitoes will be published elsewhere.

1 Bates, M., and de Zulueta, J., Amer. J. Trop. Med., 29, 129 (1949). de Zulueta, J., Amer. J. Trop. Med., 30, 325 (1950). 3 Bugher, J. C., Boshell-Manrique, J., Roca-Garcia, M., and Osorno-
Mesa, E., Amer. J. Hyg., 39, 16 (1943).

- Bates, M., Ecology, 25, 159 (1944).

\section{THE HEALTH OF ENGLAND AND WALES}

$T$

THE report of the Ministry of Health for the year ended March 31, 1949, which includes the report of the chief medical officer, Sir Wilson Jameson, for the year 1948*, shows that 1948 was remarkable in the history of health in England and Wales. Apart from the inauguration during that year of the National Health Service, the celebration of the centenary of the passing of the first Public Health Act, and the final disappearance of the Poor Law system, the total death-rate in 1948 was 10.8 and the civilian deathrate was 11.0 per thousand, both of which are the lowest figures on record. Compared with 1938, which showed the lowest standardized mortality of any year before the Second. World War, the comparative mortality index at all ages showed a decline of twenty per cent. For a year of economic struggle, this is a remarkable record. Climatic influences no doubt helped, because the winter, spring and autumn were warm, and there was no epidemic of influenza; but the many facets of public health antivity recorded in these reports show that, whatever the effects of the weather may be at any time, the constant, watchful efforts of many experts are always serving the public quietly, effectively and without publicity.

A valuable feature of the report of the chief medical officer is its analysis of the vital statistics for the years 1938-48. This shows that, among the principa] causes of death, the most striking falls during this ten-year period occurred in the death-rates from influenza, enteritis and diarrhcea, and that there were remarkable reductions in the numbers of deaths from cerebrospinal fever, diphtheria, nervous diseases, bronchitis, pneumonia and infantile diseases, while the death-rates from measles and whooping cough fell to new low levels. Deaths from cancer, however, increased, especially among males, who suffered more from cancer of the respiratory system. The birth-rate rose; but infantile mortality fell.

The epidemiological feature in England and Wales for 1948 was the absence of epidemic influenza, and no smallpox occurred in the country. There was, however, after the repeal of the Vaccination Acts in 1946, an alarming decline in vaccinations of infants; Sir Wilson Jameson gives warning that immunity to smallpox in England and Wales is now dangerously low, and he directs attention to the section of the report which deals with this subject.

* Report of the Ministry of Health for the Year ended 31st March 1949 , including the Report of the Chief Medical Officer on the State of the Public Health for the Year ended 31st December 1948. (Cmd. 7910.) Pp. xvi +374, (London: H.M. Stationery Offle, 1950.) 78. 6d. net. 
The chapter dealing with immunization against diphtheria demonstrates, on the other hand, the beneficent effects of the fight against this disease. They are shown by the reduction of notifications of diphtheria and deaths from it to less than one-tenth of those recorded in the years before immunization. Reduction in the fatality-rate of scarlet fever was partly due to penicillin and the sulphonamide drugs and partly to a natural cyclic fall in the virulence of the streptococci which cause this disease. Measles was more prevalent in 1948 than in the previous year; but there were only 327 deaths from it. Trials of a prophylactic serum against measles were in progress. As many parents know, whooping cough was also prevalent in 1948 ; but the fatality-rate $(0.51$ per cent) was lower than in any other year. This disease is, however, still a prominent cause of the deaths of infants. It is especially dangerous during the first year of life and particularly during the first six months. Although special efforts are being made to find a drug to treat it, to improve methods of diag. nosis and to make an effective prophylactic vaccine, the protection of infants from infection remains, at present, the best method of fighting the disease.

The incidence of cerebrospinal fever was low and sporadic ; but notifications of poliomyelitis continued. during the early part of 1948 at a high rate after the epidemic of 1947 and caused much anxiety. The extensive work on typhoid fever, paratyphoid fever, dysentery, enteritis and other diseases of the alimentary canal is described in some detail. That landmark in the battle of man against malaria, namely, the discovery by workers at the London School of Hygiene and Tropical Medicine of the phase of the malarial parasites which lives and multiplies in the human liver before the parasites enter the blood cells, receives the attention it deserves. Some diseases, such as anthrax and leprosy, are rare but demand a great deal of administrative labour and care. The marked fall in the incidence of syphilis recorded in 1947 continued during 1948 , although it has been less marked in the large seaports, and considerable reservoirs of this disease still exist in England and Wales. The incidence of gonorrhœa has also fallen; but it is likely that many women are infected without knowing it.

The number of deaths due to cancer increased, partly because there were more people living at the ages most susceptible to this disease. It increased more in males than in females, and two-thirds of the male increase was due to cancer of the respiratory system. An: interesting section of the report deals with acute rheumatism in children less than sixteen years of age and with chronic rheumatism. Other sections deal with the continuing expansion of the Public Health Laboratory Service, with outbreaks of milk-borne typhoid fever, paratyphoid fever and scarlet fever, with the Hospital Laboratory Service and the National Blood Transfusion Service, and with tuberculosis, mental disease, hospital planning and the dental services.

A survey of nutrition reports little change in the good nutritional state of schcol children and records satisfactory hæmoglobin levels among housewives and expectant mothers. As is well known, the treatment of flour by the 'agene' process has now ceased. The report leaves the reader in no doubt that nutrition, which is so important a means of combating disease of all kinds, is being studied in all its aspects. Not less important is the continued difficulty in providing the nursing and other staff for hospitals, and a chapter is devoted to this acute problem. The report of social survey workers describes some of the methods employed and records no real difference in the amounts of sickness recorded in 1947 and 1948. Another chapter deals with the first World Health Assembly in June 1948 and the international health work arising out of it.

In the second section of the report, the administration of the national health and welfare services are considered, and Part 2 discusses housing, local government, water, river boards and sewerage and its disposal. There are fourteen appendixes which add useful information to the great store of facts recorded in this combined report. It is, as Sir Wilson Jameson says, the work of many hands and is a monument to the effort and care expended upon the many aspects of the national health. 'The nation's gratitude is due to all these men and women who labour continually on its behalf. Whether their jobs are the humbler ones of the nurse or the clerk, or the more responsible ones of the expert, they constitute together a remark. able team. Sir Wilson Jameson, who retired early in $1950^{1}$, has played a great part in building up and eo-ordinating their efforts and can look back on a fine record during his term of office. He pays a fine tribute to Sir George Newman, who died in $1948^{2}$ and who, as a predecessor in office to Sir Wilson, had guided public health activities for a quarter of a century.

G. LAPAGE

Nature, 165, 753 (1950).

${ }^{2}$ Nature, 161, 1001 (1948).

\section{RESEARCH AND DEVELOPMENT AT BAKELITE, LTD.}

$\mathrm{O}^{\mathrm{N}}$ June 21, Bakelite, Ltd., opened their new research and development laboratories at Birmingham to a representative gathering of those interested in both the scientific and industrial progress of high-polymer science and technology. Although only part of the manufacturing site of this concern is located at Tyseley in Birmingham, the research and development activities of the firm are mainly centred there. The visit presented a unique opportunity for seeing how one of the old-established branches of the industry has developed on the industrial side, and how, with the advance of knowledge in the science of high polymers, that science has been integrated with technology-a first pre-requisite of a healthy and forward-looking industry.

One of the major activities concerns the thermosetting resins derived from phenols and formaldehyde and from urea and formaldehyde. In spite of the extensive use of such resins in a host of applications such as laminated materials for electrical purposes, cements and adhesives, moulding powders and oil. soluble resins for paints, the chemical process involved in the manufacture of the resin as such is to a very large extent built on empirical knowledge. That does not mean that precise methods of the control of processes and the checking of the quality of the product are not used at every stage. In fact, the visit demonstrated clearly just how much can be contributed by instrumentation to the reproducibility and efficiency of the manufacturing processes $\mathrm{em}$ ployed. 'The older autoclaves or 'stills', as they are called, were devoid of control devices, and the whole success of synthesis depended to a large extent on the skill of the operators. In the most up-to-date 